\title{
Successful treatment of Takayasu's arteritis in an HIV positive adult patient with long term follow up
}

\author{
Marie DeLuca ${ }^{1}$, Philip A. Gruppuso², Edward J. Wing*3 \\ ${ }^{1}$ Alpert Medical School of Brown University, Providence, RI, USA \\ ${ }^{2}$ Department of Pediatrics, Warren Alpert Medical School, Brown University, Providence, RI, USA \\ ${ }^{3}$ Department of Medicine, Warren Alpert Medical School, Brown University, Providence, RI, USA
}

Received: July 19, 2016

DOI: $10.5430 /$ crim.v3n $4 \mathrm{p} 14$
Accepted: August 11, $2016 \quad$ Online Published: August 16, 2016

URL: http://dx.doi.org/10.5430/crim.v3n4p14

\begin{abstract}
Although vasculitides occur in patients with HIV, only 4 previous cases of Takayasu's arteritis (TA) have been reported in HIV patients. We describe the first case of TA in an HIV positive patient with successful treatment and long term follow up. A 38-year-old woman who was HIV positive for the last 5 years on antiretroviral medications presented with increasing pain in her left arm. Blood pressure and pulse were unrecordable in that arm. Laboratory testing revealed hemoglobin 7.9 g/dl, CRP 98.8 $\mathrm{mg} / \mathrm{L}, \mathrm{CD} 4675$ cells/ $\mu$ l and HIV viral load $<48$ copies/ml. Both MRA and standard angiography demonstrated occlusion of the left subclavian artery from its origin to the vertebral artery where it was reconstituted via retrograde flow from the left vertebral artery and left carotid artery branches (subclavian steal). Narrowing of the vertebral artery was also noted. Treatment with prednisone and methotrexate for one year improved her symptoms and stabilized her lesions without infectious complications. Follow up 4 years after stopping therapy revealed mild symptoms and stable lesions on MRA.
\end{abstract}

Key Words: HIV, Takayasu's arteritis, Subclavian steal, Prednisone, Methotrexate

\section{INTRODUCTION}

Rheumatological diseases are increasingly being recognized as comorbid conditions in HIV positive patients in the U.S. ${ }^{[1,2]}$ Ranging from systemic lupus erythematous, a disease that often improves following HIV infection, to zidovudine-associated myopathy, a condition seen only in HIV positive patients, these diseases present unique challenges in diagnosis and treatment.

Takayasu's arteritis is a large vessel vasculitis affecting the aorta and its branches that is potentially life threatening. It is usually treated with glucocorticoids, although relapses are frequent. ${ }^{[3-5]}$ There have been four previously reported cases of Takayasu's arteritis (TA) in HIV positive patients, ${ }^{[6-9]}$ but to the best of our knowledge, there are no reported cases of successful treatment of TA in an HIV positive adult with long term follow-up. The underlying immunosuppression of HIV positive patients coupled with the added immunosuppressive effects of glucocorticoids and other immunosuppressive drugs increase risks for infectious complications during treatment of TA. In this report, we discuss the diagnosis and successful treatment with a 5-year follow up of TA in an adult HIV positive patient.

\section{Case report}

A 38-year-old HIV positive woman, originally from Honduras, presented with pain upon elevation of her left arm,

${ }^{*}$ Correspondence: Edward J. Wing, MD, Professor; Email: Edward_Wing_MD@brown.edu; Address: The Miriam Hospital, 164 Summit Avenue, Providence, RI 02906, USA. 
weight loss and fatigue. The pain had progressively worsened over the previous ten-months and was interfering with her ability to work. The pain was accompanied by the recent onset of numbness in her fifth, fourth, and one half of her third digits, and Raynaud's-type syndrome in her left hand. She denied any neurologic symptoms.

Past medical history included HIV diagnosed 5 years prior to presentation and treated with lamivudine, didanosine, and efavirenz. One year later, she had fever, anemia and pyelonephritis which was treated successfully with antibiotics. Because of a concern for lupus erythematosus, serological testing and a renal biopsy were obtained. The antinuclear antigen titer was 1:320 but the anti-double-stranded DNA antibody and the anti-Smith antigen antibody tests were negative. The renal biopsy was consistent with pyelonephritis. Therefore, lupus erythematosus was considered unlikely; she received no therapy and had no further symptoms.

On physical examination, the blood pressure in her right arm was $130 / 46 \mathrm{mmHg}$ and the pulse was $98 / \mathrm{min}$. In her left arm, the blood pressure was unrecordable and the left brachial and radial pulses were absent. The left extremity was cool without discoloration. Left hand capillary refill time was within normal limits. The remainder of the physical examination including the neurological examination was unremarkable. At presentation, the patient had a CD4 count $675 / \mu 1$, viral load < 48 copies $/ \mathrm{ml}$, hemoglobin $7.9 \mathrm{~g} / \mathrm{dl}$, creatinine 0.71 $\mathrm{mg} / \mathrm{dl}$, ESR $140 \mathrm{~mm} / \mathrm{hour}$, CRP $98.8 \mathrm{mg} / \mathrm{L}$, and ANA titer $1: 40$.

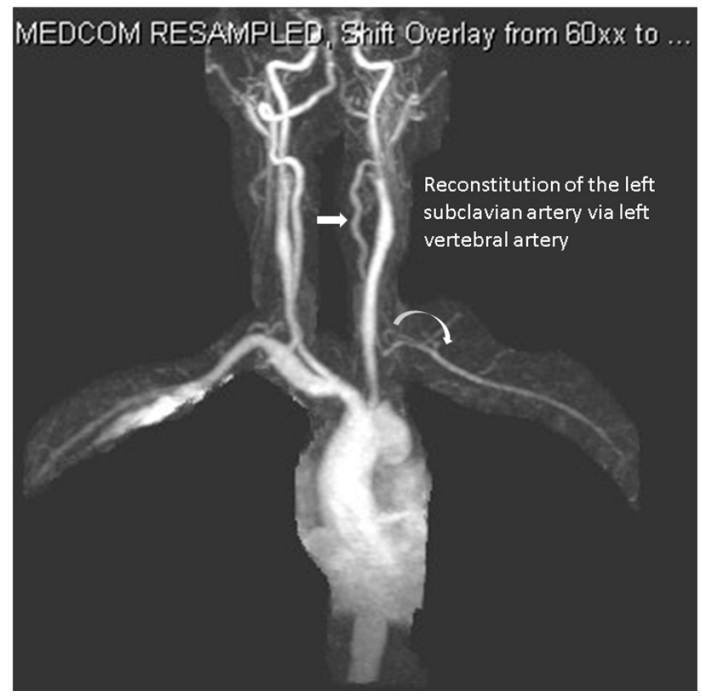

Figure 1. MRA demonstrating reconstitution of the left subclavian artery via left vertebral artery
A magnetic resonance angiogram (MRA) demonstrated occlusion of the left subclavian artery from its origin to the vertebral artery where it was reconstituted via the left vertebral artery and left carotid artery branches, consistent with subclavian steal (see Figure 1). Findings were confirmed with catheter angiogram and aortogram (see Figure 2). Highgrade stenosis of the vertebral artery at its origin and moderately severe narrowing and tapering of the left vertebral artery were also noted. There was no evidence of aortic involvement. These findings along with her clinical presentations were consistent with a diagnosis of Takayasu's arteritis (5/6 criteria by the American College Rheumatology guidelines).

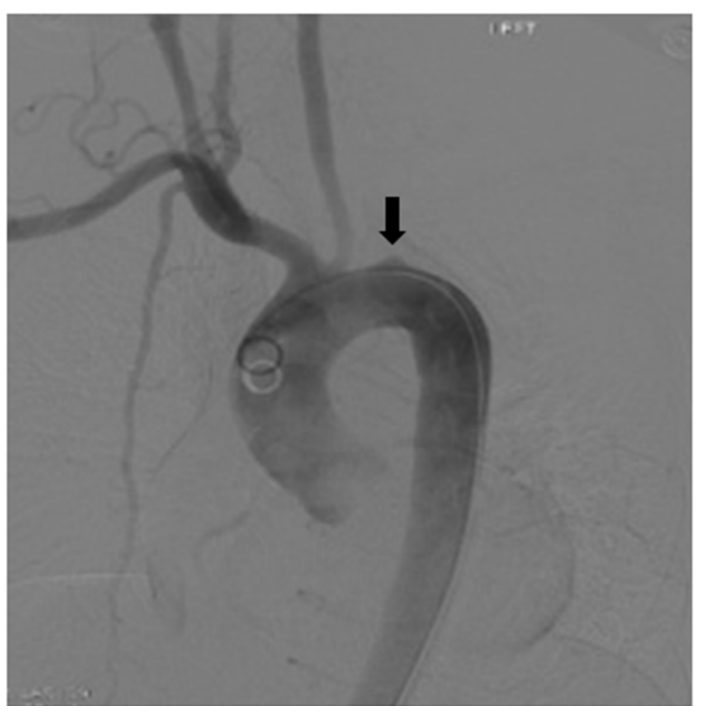

Figure 2. Catheter aortogram showing occlusion at the origin of the left subclavian artery

The patient received methylprednisolone IV for 24 hours and then was started on prednisone $45 \mathrm{mg}$ by mouth. Trimethoprim-sulfamethoxazole prophylaxis was started because of the dual risk of prolonged corticosteroids and HIV.

Ten days after diagnosis and initiation of treatment, the patient reported that her symptoms had improved, and 3 weeks after starting treatment she felt well enough to return to work. Two months after beginning treatment she developed Cushingoid facies. Three months after diagnosis a repeat MRA showed that the subclavian steal and vertebral artery stenosis were stable. Her CD4 count fell below 200 temporarily but she did not develop opportunistic infections. The patient's prednisone was slowly tapered. Six months after beginning therapy, methotrexate was added for its corticosteroid sparing effect. The course of the patient's treatment is shown in Table 1. 
Table 1. Treatment of Takayasu's arteritis

\begin{tabular}{llll}
\hline $\begin{array}{l}\text { Time after initiation } \\
\text { of therapy }\end{array}$ & Prednisone oral & Methotrexate oral & Comments \\
\hline Initiation & $45 \mathrm{mg} /$ day & none & Improved symptoms within 10 days; returned to work within 3 weeks \\
2 months & $45 \mathrm{mg} /$ day & none & Developed Cushingoid facies \\
3 months & $45 \mathrm{mg} /$ day; started to taper & none & MRA showed stable lesions \\
6 months & $20 \mathrm{mg} /$ day & $10 \mathrm{mg} /$ week & \\
8 months & $17.5 \mathrm{mg} /$ day & $15 \mathrm{mg} /$ week & Scheduled to reduce prednisone to $10 \mathrm{mg} /$ day and increase methotrexate to 20 \\
\hline 12 months & $15 \mathrm{mg} /$ day & $17.5 \mathrm{mg} /$ week & mg/day \\
\hline
\end{tabular}

Note. Subsequent to the last visit 12 months after beginning therapy, the patient stopped all medications and was lost to follow up for 6 months.

One year after starting therapy, the patient stopped taking all medications including her antiretroviral regimen and she was lost to follow up for six months. Upon return to medical care, she resumed antiretroviral therapy (efavirenz/emtricitabine/tenofovir disoproxil) but did not resume methotrexate or prednisone. She continued to have mild left arm pain that increased on elevation. Blood pressure and radial pulse in her left arm continued to be unrecordable. Her ESR was $10 \mathrm{~mm} /$ hour and CRP was $12.6 \mathrm{mg} / \mathrm{L}$. A third MRA performed approximately 2 years after stopping therapy for TA (3 years after diagnosis of TA), showed persistent subclavian steal but improvement in the vertebral artery narrowing with no further occlusion of major vessels. She remains clinically stable 4 years after stopping therapy (5 years after diagnosis) and continues to work.

\section{Discussion}

According to a $2011 \mathrm{CDC}$ estimate, there are 1.2 million people in the US living with $\mathrm{HIV},{ }^{[10]}$ whereas the incidence of TA is approximately 2-3 per million people. ${ }^{[1]}$ Therefore, approximately 3 cases of TA in HIV positive patients would be expected in the U.S./year. Rheumatological conditions, including vasculitides, have been reported in HIV positive patients, ${ }^{[1]}$ but TA has been reported in only four cases, only one of which was from the U.S. ${ }^{[6,8,9]}$ Shingadia reported a case of a 16-year-old male patient with transfusion acquired HIV, TA and tuberculosis who was successfully treated for his TA with prednisolone $(1 \mathrm{mg} / \mathrm{kg})$ for one year. The patient was asymptomatic following treatment and no further followup was reported. Baruteau reported a case of tuberculosis, HIV, and TA in a 9-year-old African boy successfully treated with glucocorticoids and well three years after treatment. Kalungi reported TA in a 23-year-old HIV positive woman from Uganda who died of a cerebral infarction secondary to carotid artery obliteration and stenosis. Ojeda-Burgos reported a 46-year-old Spanish woman with HIV successfully treated for TA with prednisone $(1 \mathrm{mg} / \mathrm{kg}$ /day) with a follow up of 3 months. To our knowledge, however, successful treat- ment of TA in an HIV positive adult with long term follow up has not been reported.

Glucocorticoid therapy is the mainstay of treatment for TA and usually induces remission ${ }^{[5]}$ although relapse during tapering occurs in up to $70 \%$ of patients. ${ }^{[3]}$ As a result steroid sparing regimens such as methotrexate or azothioprine are often used. In conditions other than TA, short courses of prednisone ( 8 weeks) have been shown to be safe in patients with advanced HIV-1 infection ${ }^{[12,13]}$ and other vasculitides in HIV positive patients have been successfully treated with prednisone. ${ }^{[2]}$ The safety of long term glucocorticoid treatment in HIV positive patients, however, has not been established. Revascularization may be necessary in patients with TA if symptoms related to the neurologic or cardiovascular system occur, or if there is progressive limb ischemia.

In our case, an initial pulse of IV methylprednisolone followed by oral prednisone successfully reduced symptoms, allowing the patient to return to work. Subsequent use of weekly methotrexate as a steroid-sparing regimen permitted prolonged therapy. The patient did experience a temporary drop in her CD4 count below 200, but did not suffer opportunistic infections. Although relapses are common in TA, our patient continues in remission, four years after discontinuing therapy. She does experience intermittent arm pain on elevation and occasional headaches, but denies constitutional symptoms. This is consistent with her follow up MRA two years after stopping therapy that showed a stable subclavian steal, without progressive inflammation of other major vessels.

This case is a classic presentation of an unusual illness, of which only 4 cases have been reported in HIV positive patients previously. The use of prednisone followed by a corticosteroid sparing medication, methotrexate, for 1 year was successful in stabilizing her disease and reducing her symptoms without significant side effects. This rare but serious vasculitis should be considered in HIV positive patients presenting with characteristic signs and symptoms; immunosup- 
pressive therapy was effective and safe in this case.

\section{Funding}

The authors received no financial support for the research, authorship, and-or publication of this article.

\section{CONFLICTS OF INTEREST DISCLOSURE}

The authors declare no potential conflict of interest with respect to the research, authorship, and/or publication of this article.

\section{REFERENCES}

[1] Maganti RM, Reveille JD, Williams FM. Therapy insight: the changing spectrum of rheumatic disease in HIV infection. Nat Clin Pract Rheumatol. 2008; 4(8): 428-38. PMid:18577999 http: $/ / \mathrm{dx}$.doi.org/10.1038/ncprheum0836

[2] Patel Ni, Patel Ne, Khan T, et al. HIV infection and clinical spectrum of associated vasculitides. Curr Rheumatol Rep. 2011; 13(6): 506-12. PMid:21989711 http://dx.doi.org/10.1007/s11926-011-0 214-6

[3] Maksimowicz-McKinnon K, Clark TM, Hoffman GS. Limitations of therapy and a guarded prognosis in an American cohort of Takayasu arteritis patients. Arthritis Rheum. 2007; 56(3): 1000-9. PMid:17328078 http://dx.doi.org/10.1002/art.22404

[4] Johnston SL, Lock RJ, Gompels MM. Takayasu arteritis: a review. J Clin Pathol. 2002; 55(7): 481-6. PMid:12101189 http: $/ / \mathrm{dx}$.doi.org/10.1136/jcp.55.7.481

[5] Park MC, Lee SW, Parl YB, et al. Clinical characteristics and outcomes of Takayasu's arteritis: analysis of 108 patients using standardized criteria for diagnosis, activity assessment, and angiographic classification. Scand J Rheumatol. 2005; 34(4): 284-92. PMid:16195161 http://dx.doi.org/10.1080/03009740510026526

[6] Shingadia D, Das L. Takayasu's arteritis in a human immunodeficiency virus-infected adolescent. Clin Infect Dis. 1999; 29(2): 458-9. PMid:10476770 http://dx.doi.org/10.1086/520244

[7] Baruteau AE, Martins RP, Boulmier D, et al. Acquired left ventricular submitral aneurysms in the course of Takayasu arteritis in a child. Congenit Heart Dis. 2012; 7(1): 76-9. PMid:21696552 http://dx.doi.org/10.1111/j.1747-0803.2011.00537.x

[8] Kalungi S, Kigonya E, Eyoku S, et al. Takayasu's arteritis (pulseless disease) in Uganda. Afr Health Sci. 2004; 4(3): 185-7. PMid: 15687072

[9] Ojeda-Burgos GG-R, Aguilar-Buevas R, Marquez-Solero M. Takayasu arteritis in an HIV infectem woman. Case Reports in Internal Medicine. 2014; 1(2).

[10] CDC. Monitoring selected national HIV prevention and care objectives by using HIV surveillance data-United States and 6 U.S. dependent areas-2011. HIV Surveillance Supplemental Report. 2013; 18(5).

[11] Richards BL, March L, Gabriel SE. Epidemiology of large-vessel vasculidities. Best Pract Res Clin Rheumatol. 2010; 24(6): 87183. PMid:21665132 http://dx.doi.org/10.1016/j.berh. 20 10.10.008

[12] Wallis RS, Kalayjian R, Jacobson JM, et al. A study of the immunology, virology, and safety of prednisone in HIV-1-infected subjects with CD4 cell counts of 200 to $700 \mathrm{~mm}(-3)$. J Acquir Immune Defic Syndr. 2003; 32(3): 281-6. PMid:12626887 http: //dx.doi.org/10.1097/00126334-200303010-00006

[13] McComsey GA, Whalen CC , Mawhorter SD, et al. Placebocontrolled trial of prednisone in advanced HIV-1 infection. AIDS. 2001; 15(3): 321-7. PMid:11273211 http://dx.doi.org/10.10 97/00002030-200102160-00004 